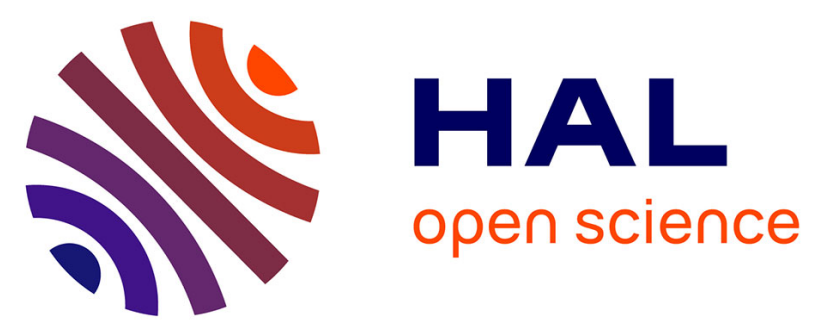

\title{
Negative effects of divalent mineral cations on the bioaccessibility of carotenoids from plant food matrices and related physical properties of gastro-intestinal fluids
}

Joana Corte-Real, Marie Bertucci, Christos Soukoulis, Charles Desmarchelier, Patrick Borel, Elke Richling, Lucien Hoffmann, Torsten Bohn

\section{To cite this version:}

Joana Corte-Real, Marie Bertucci, Christos Soukoulis, Charles Desmarchelier, Patrick Borel, et al.. Negative effects of divalent mineral cations on the bioaccessibility of carotenoids from plant food matrices and related physical properties of gastro-intestinal fluids. Food and Function, 2017, 8 (3), pp.1008-1019. 10.1039/C6FO01708H . inserm-01479975v2

\section{HAL Id: inserm-01479975 \\ https://www.hal.inserm.fr/inserm-01479975v2}

Submitted on 9 Apr 2018

HAL is a multi-disciplinary open access archive for the deposit and dissemination of scientific research documents, whether they are published or not. The documents may come from teaching and research institutions in France or abroad, or from public or private research centers.
L'archive ouverte pluridisciplinaire HAL, est destinée au dépôt et à la diffusion de documents scientifiques de niveau recherche, publiés ou non, émanant des établissements d'enseignement et de recherche français ou étrangers, des laboratoires publics ou privés. 


\section{Negative effects of divalent mineral cations on the bioaccessibility of}

\section{intestinal fluids}

4 Joana Corte-Real ${ }^{\mathrm{a}, \mathrm{d}}$, Marie Bertucci ${ }^{\mathrm{d}}$, Christos Soukoulis ${ }^{\mathrm{d}}$, Charles Desmarchelier ${ }^{\mathrm{b}}$, Patrick

$5 \quad$ Borel $^{\mathrm{b}}$, Elke Richling ${ }^{\mathrm{c}}$, Lucien Hoffmann ${ }^{\mathrm{d}}$, Torsten Bohn ${ }^{1, \mathrm{a} *}$

6

$7 \quad{ }^{a}$ Luxembourg Institute of Health (LIH), Population Health Department, 1 a-b, rue Thomas

8 Edison, L-1445 Strassen, Luxembourg

9 b NORT, INRA, INSERM, Aix-Marseille Université, 13005, Marseille, France

$10{ }^{\mathrm{c}}$ Food Chemistry and Toxicology, Department of Chemistry, University of Kaiserslautern,

11 Erwin-Schroedinger-Strasse 52, D-67663 Kaiserslautern, Germany

$12{ }^{\mathrm{d}}$ Luxembourg Institute of Science and Technology (LIST), Environmental Research and

13 Innovation (ERIN) Department, 41 rue du Brill, L-4422 Belvaux, Luxembourg

$15 *$ To whom correspondence should be addressed:

16 Dr. Torsten Bohn

17 e-mail: torsten.bohn@gmx.ch

18 phone: $+352-621-216-637$

19 fax: +352-621-470-264

21 Running title: Divalent minerals affect carotenoid bioaccessibility and digesta rheology

Word count: 6280 


\section{Abstract}

Carotenoid intake and tissue levels have been frequently associated with reduced risk of chronic diseases. However, their bioavailability is low and influenced by many dietary related parameters. Divalent mineral cations have been suggested to interfere with carotenoid digestion and to hamper micellarization, a prerequisite for their uptake, via complexation of bile salts and precipitation of fatty acids. In the present investigation, we have evaluated the effects of increasing concentrations of magnesium $(0-300 \mathrm{mg} / \mathrm{L})$, calcium $(0-1500 \mathrm{mg} / \mathrm{L})$, zinc $(0-$ $200 \mathrm{mg} / \mathrm{L})$, and sodium (0 - $1500 \mathrm{mg} / \mathrm{L}$; control monovalent cation), on carotenoid bioaccessibility from frequently consumed food items rich in carotenoids (tomato juice, carrot juice, apricot nectar, spinach and field salad), following simulated gastro-intestinal digestion. In addition, physicochemical parameters of digesta (macroviscosity, surface tension), micelle size, and zeta-potential were evaluated. All divalent minerals (DM) reduced bioaccessibility of total carotenoids $(\mathrm{P}<0.01)$, as well as of individual carotenoids. Calcium and magnesium led to reductions of up to $100 \%$ at the 2 highest concentrations. Curiously, sodium increased $(\mathrm{P}<0.01)$ carotenoid bioaccessiblity of most investigated matrices. The absolute value of the zeta-potential decreased with increasing concentrations of DM, suggesting a decreased stability of the colloidal digesta dispersion. Viscosity decreased, except for apricot nectar samples, while surface tension increased with $\mathrm{DM}$ concentration $(\mathrm{P}<0.05)$. Thus, at physiological ranges, calcium and magnesium could negatively impact carotenoid bioavailability, while for zinc, negative effects were only seen at supplemental concentrations. The potential negative effects of DM on carotenoid bioavailability should be further studied in vivo.

Keywords: phytoene; phytofluene; calcium; magnesium; digestion; micellization; surface tension; zeta-potential; bile salts; soap formation. 
50 Carotenoids are secondary metabolites, found across all kingdoms of life. As pigments, absorbing light in the visible spectrum, carotenoids colour many fruits and vegetables in orange, red and yellow ${ }^{1,2}$. Structurally, they are composed of a C-40 skeleton with a partly conjugated double-bond system that is the key to many of the carotenoids' characteristics. One important property is the ability to absorb excess energy from reactive oxygen species and to quench singlet oxygen, meaning that they can act as anti-oxidants ${ }^{1,3,4}$. This anti-oxidant potential coupled with anti-inflammatory properties $^{5}$ is of particular interest from a public health perspective for the prevention and delayed progression of several chronic diseases ${ }^{6}$, including eye related degenerative diseases ${ }^{7}$, ardiovascular diseases $^{8}$, diabetes ${ }^{9}$ and prostate cancer $^{10,11}$. In addition, certain carotenoids, including $\beta$-carotene, $\alpha$-carotene and $\beta$ cryptoxanthin, are also sources for vitamin A production by the human body.

Nevertheless, the bioactivity of carotenoids is firstly dependent on their bioavailability, i.e. the fraction of ingested carotenoids that is available for physiological functions and/or storage in organs and tissues ${ }^{12}$. The first limiting factor of carotenoid bioavailability is their release from the food matrix and their inclusion in bile acid-lipid mixed micelles ${ }^{13,14}$, i.e. their bioaccessibility. This step is mainly affected by 1) dietary factors (type and amount of fiber and lipids, form of storage of carotenoids in the matrix, among other ${ }^{15-20}$, and 2) host-related physiological factors (enzyme and bile acid concentrations secreted, gastric and intestinal $\mathrm{pH}$, etc. $)^{21,22}$.

The presence of divalent minerals during gastro-intestinal digestion, particularly calcium and magnesium, has been hypothesized to negatively affect the bioaccessibility of carotenoids ${ }^{23,24}$. Divalent mineral cations are naturally present in the human gut and are part of our diet. The effects of the interactions between divalent cations and lipids ${ }^{25,26}$, and divalent cations and bile $\operatorname{acids}^{27,28}$ have already been investigated. It has been hypothesized that during digestion, these 
cations bind free fatty acids and bile acids to form fatty acid soaps and bile salts of generally low solubility, respectively. Depending on the cation concentration, this could lead to precipitations, removing lipids from the system and ultimately impairing the formation of bile acid-lipid mixed micelles. Previously, we have scrutinized in vitro employing simulated gastrointestinal digestion the effects of the presence of divalent minerals, including calcium, magnesium and zinc, on the bioaccessibility of carotenoids alone and from $\operatorname{spinach}^{23,24}$. The concentration-dependent effect of these minerals appeared obvious, with calcium and magnesium reducing significantly, at increasing concentrations, carotenoid fractional bioaccessibility. However, the effect of different food matrices including solid vs. liquid form and thus different complexity on carotenoid bioaccessibility has so far not been studied. Furthermore, we have previously observed an association between decreased viscosity and increased surface tension and carotenoid bioaccessibility ${ }^{23}$.

Here, we strived to obtain additional insights in this regard from real food matrices, also with respect to micellar stability, as it could be speculated that an altered dynamic of the micellarization process may impinge on micelle formation. The objective of the present study was thus to evaluate the impact of various concentrations of the divalent minerals calcium, magnesium and zinc, present during simulated digestion, on the bioaccessibility of individual carotenoids from different frequently consumed food items rich in carotenoids, and to better understand the mechanism of action of divalent minerals by scrutinizing viscosity and surface tension changes during digestion.

\section{EXPERIMENTAL}

\section{Chemicals and standards}

Digestive enzymes, i.e., pepsin (porcine, $\geq 250$ units/mg solid, measured as trichloroacetic acidsoluble products using hemoglobin as substrate) and pancreatin (porcine, 4x US Pharmacopeia 
specifications of amylase, lipase and protease), and porcine bile extract were purchased from Sigma-Aldrich (Bornem, Belgium). The solvents hexane, diethyl ether, methanol $(\mathrm{MeOH})$, acetonitrile (ACN), and dichloromethane (DCM) were purchased from Carl Roth $\mathrm{GmbH}+\mathrm{Co}$. KG (Karlsruhe, Germany), and all solvents were from Rotisol ${ }^{\circledR}$ HPLC grade. Acetone was purchased from VWR (Leuven, Belgium), and methyl tert-butyl ether (MTBE) from SigmaAldrich (Bornem, Belgium). Potassium hydroxide $(\mathrm{KOH})$, sodium hydroxide $(\mathrm{NaOH})$, hydrochloric acid $(\mathrm{HCl})$, calcium chloride anhydrous and zinc chloride anhydrous were purchased from VWR (Leuven, Belgium). Sodium bicarbonate and sodium chloride were purchased from Merck (Darmstadt, Germany), while magnesium chloride anhydrous was acquired at Sigma-Aldrich, and ammonium acetate from VEL ${ }^{\circledR}$ (Leuven, Belgium). Lycopene, $\beta$-carotene and $\beta$-apo-8'-carotenal standards were acquired from Sigma-Aldrich; violaxanthin, neoxanthin, lutein, phytoene and phytofluene standards were purchased from CaroteNature GmbH (Ostermundigen, Switzerland). Unless otherwise specified, all products were of analytical grade or higher. $18 \mathrm{M} \Omega$ water was prepared with a purification system from Millipore (Brussels, Belgium) and used throughout the study.

\section{Food matrices and test meals}

Five food items were investigated: Eden Organic 100\% Carrot Juice (other ingredients: lemon juice); Granini Apricot Nectar from concentrate (minimum fruit content: 40\%) (other ingredients: sugar, concentrate from lemon juice, ascorbic acid); Rauch 100\% Tomato Juice from concentrate (other ingredients: $0.3 \%$ salt, citric acid); frozen spinach leaves (Spinachia oleracea) from CORA supermarket (Foetz, Luxembourg); and fresh field salad (Valerianella locusta) from Delhaize (Belval, Luxembourg) supermarket. Matrices were chosen based on their carotenoid profile, and in order to cover the range of several of the most common carotenoids present in human diet. Fruit juices were aliquoted into $50 \mathrm{~mL}$ amber conical 
propylene tubes, frozen in liquid nitrogen and stored at $-80^{\circ} \mathrm{C}$ until the day of the experiments. Spinach aliquots were prepared as follows: i) spinach was left to defreeze; ii) the excess water was drained and the leaves were pat dry; iii) spinach was homogenized stepwise in a Grindomix GM 200 (Retsch, Aartselaar, Belgium) at 3, 4 and 5 x $1000 \mathrm{rpm}$ (5 seconds each); iv) the homogenized spinach was weighted and aliquoted into polypropylene sample containers, flushed with argon and stored at $-80^{\circ} \mathrm{C}$. Aliquots of field salad were prepared in a similar fashion (step iii and iv).

To promote the solubilization of dietary carotenoids and micelle formation during gastrointestinal digestion, we have chosen to add coffee creamer (10\% fat) to the tested matrices, as a natural source of triglycerides and phospholipids, which are essential for the formation of mixed bile-lipid micelles. Similar dairy products have been used previously in our lab in order to foster carotenoid bioaccessibility ${ }^{24,29,30}$. INEX coffee creamer (10\% fat) was purchased at a local supermarket (Delhaize).

137

\section{Simulation of gastro-intestinal digestion and factors investigated}

To investigate the effect of divalent minerals (calcium, magnesium and zinc), we tested the following concentrations: calcium 0, 250, 500 and $1000 \mathrm{mg} / \mathrm{L}$; magnesium 0, 100, 200 and 300 $\mathrm{mg} / \mathrm{L}$; zinc $0,12.5,25,50,100$ and $200 \mathrm{mg} / \mathrm{L}$; and sodium 0, 375, 750 and $1500 \mathrm{mg} / \mathrm{L}$, which of the mineral per volume of digesta, we assumed a total volume of $2 \mathrm{~L}$ of intestinal fluids during gastrointestinal (GI) digestion. For the purposes of this study, we have defined as physiological a range of cation concentrations up to the daily RDA/AI (dissolved in $2 \mathrm{~L}$ ), and 
minerals were prepared with a physiological saline solution. The in vitro gastro-intestinal digestion protocol was adapted from Biehler et al. (2011) ${ }^{22}$ and is described below.

Gastric phase. The previously prepared frozen aliquots of the food matrices were thawed, and $4 \mathrm{~g}$ of matrix were weighed into $50 \mathrm{~mL}$ amber Falcon tubes. To improve carotenoid bioaccessibility, $2 \mathrm{~mL}$ of coffee creamer $\left(10 \%\right.$ fat) were added to each test meal ${ }^{24,29}$. To simulate the gastric passage, varying volumes of physiological saline and of a standard solution of the investigated mineral were added to equal final volumes of the test meal. The volumes of the physiological saline and of the mineral solution were determined based on the desired cation concentration at the intestinal phase. Test meal was acidified by adding $2 \mathrm{~mL}$ of pepsin (40 $\mathrm{mg} / \mathrm{mL}$ in $\mathrm{HCl} 0.01 \mathrm{M}$ ), and the $\mathrm{pH}$ was adjusted for each test meal at the beginning of the gastric phase to a $\mathrm{pH}$ of 3 . The tubes were sealed with Parafilm ${ }^{\circledR}$, and incubated during $1 \mathrm{~h}$ at $37^{\circ} \mathrm{C}$, in a shaking water bath (GFL 1083 from $\mathrm{VEL}^{\circledR}$, Leuven, Belgium) with reciprocating motion at 100 strokes per minute.

Intestinal Phase. At the end of the incubation period, a volume of $9 \mathrm{~mL}$ of solution of porcine bile extract $(24 \mathrm{mg} / \mathrm{mL})$ and pancreatin $(4 \mathrm{mg} / \mathrm{mL})$ in $\mathrm{NaHCO}_{3}(0.1 \mathrm{M})$ was added to the simulated digestive fluids, and the $\mathrm{pH}$ was adjusted to 7 . The final volume of the samples was brought to $50 \mathrm{~mL}$ with physiological saline. The tubes were once again sealed with Parafilm and to simulate the intestinal passage, samples were incubated for $2 \mathrm{~h}$ in a shaking water bath $(100 \mathrm{rpm})$ at $37^{\circ} \mathrm{C}$. At the end of the gastro-intestinal digestion, aliquots of $12 \mathrm{~mL}$ were transferred into $15 \mathrm{~mL}$ Falcon tubes and centrifuged (Thermo Scientific Heraeus Multifuge $\mathrm{X} 3 \mathrm{R}$ ) at $4700 \mathrm{~g}$ for $1 \mathrm{~h}$, at $4{ }^{\circ} \mathrm{C}$. After centrifugation, a $6 \mathrm{~mL}$ aliquot was collected from the middle aqueous fraction with a syringe and hypodermic needle, and filtered through a $0.2 \mu \mathrm{m}$ 
nylon membrane filter (Acrodisc ${ }^{\circledR} 13 \mathrm{~mm}$ Syringe Filters, PALL Life Sciences, Ann Harbor, MI) into a new $15 \mathrm{~mL}$ Falcon tube. Four $\mathrm{mL}$ were then taken for extraction of carotenoids.

\section{Extraction of carotenoids}

Extraction from food matrices. Aliquots of $4 \mathrm{~g}$ of food material were weighted into $50 \mathrm{~mL}$ falcon tubes. Spinach and field salad were wetted with $5 \mathrm{~mL}$ of methanol, and $1 \mathrm{~mL}$ of $30 \%$ aqueous $\mathrm{KOH}$ was added for saponification of chlorophylls. Samples were then vortexed, sonicated at $37 \mathrm{kHz}$ for $10 \mathrm{~min}$ in an ultrasonic bath (Elmasonic Ultrasonic Bath, Elma, Mägenwil, Switzerland), and further incubated in the dark for 20 min (still with $\mathrm{KOH}$ ) at room temperature. Samples were then centrifuged for $5 \mathrm{~min}$ at $1300 \mathrm{~g}$ at $4^{\circ} \mathrm{C}$. The supernatant was collected into a second $50 \mathrm{~mL}$ Falcon tube. The following extraction steps were similar for both green leafy matrices and fruits juices. Matrices were extracted once with $9 \mathrm{~mL}$ hexane:acetone (1:1), vortexed, sonicated for $5 \mathrm{~min}$, and centrifuged $\left(5 \mathrm{~min}, 1300 \mathrm{~g}, 4^{\circ} \mathrm{C}\right)$. The supernatants were collected into a second $50 \mathrm{~mL}$ Falcon tube, while for saponified samples the supernatant was combined with the methanol phase. Extraction was repeated once with $9 \mathrm{~mL}$ of hexane and a second time with $9 \mathrm{~mL}$ hexane plus $4 \mathrm{~mL}$ of saturated $\mathrm{NaCl}$. Supernatants were combined in the second tube. For the extraction of the fruit juice matrices, only half of the above mentioned volumes were used. All matrices were extracted once more with $4 \mathrm{~mL}$ of diethyl ether, vortexed, sonicated and centrifuged, and the supernatant was combined with the previously collected organic phases. To promote phase separation from water residues, samples were spun down at $1300 \mathrm{~g}$, for $1 \mathrm{~min}$, at $4^{\circ} \mathrm{C}$. When water was present, the organic phase was transferred into a third tube, and the total volume was written down prior to collecting a $10 \mathrm{~mL}$ aliquot for evaporation. The aliquots of the combined extracts were dried under a stream of nitrogen using a TurboVapLV (Biotage, Eke, Belgium) apparatus, for $45 \mathrm{~min}$ at $25^{\circ} \mathrm{C}$. Dried extracts were re-dissolved in 5 to $7 \mathrm{~mL}$ of MTBE:MeOH (3:7), filtered through a $0.2 \mu \mathrm{m}$ PVDF syringe filter, and the filter was rinsed with $1 \mathrm{~mL}$ of MTBE:MeOH (3:7). 
200 Extraction from the bioaccessible fraction. A $4 \mathrm{~mL}$ aliquot of the bioaccessible fraction was extracted with $6 \mathrm{~mL}$ of hexane:acetone $(2: 1)$ - in the case of green leafy matrices an additional $1 \mathrm{~mL}$ of aqueous $\mathrm{KOH}(30 \%)$ was added for saponification - vortexed and centrifuged for 2 $\min$ at $4000 \mathrm{~g}$, at $4^{\circ} \mathrm{C}$. The supernatant was transferred to a new $15 \mathrm{~mL}$ falcon tube. The bioaccessible fraction was re-extracted once with $5 \mathrm{~mL}$ of hexane, and a second time with 5 $\mathrm{mL}$ of diethyl ether. The combined and homogenized organic phases were centrifuged, during $2 \mathrm{~min}$ at $4000 \mathrm{~g}$, to separate the organic phase from any water carried over during extraction. The totality of the organic phase was transferred into a new tube, and evaporated under a stream of nitrogen on a TurboVap for $45 \mathrm{~min}$ at $25^{\circ} \mathrm{C}$. The dried carotenoid extracts were spiked with an appropriate amount of internal standard (IS), $\beta$-apo- 8 '-carotenal, of known concentration $(10 \mu \mathrm{g} / \mathrm{mL})$ to obtain a final concentration of $1 \mu \mathrm{g} / \mathrm{mL}$ in the sample, and re-dissolved in 500 $\mu \mathrm{L}$ of MTBE:MeOH (3:7). Samples were filtered through a $0.2 \mu \mathrm{m}$ PVDF syringe filter (PALL Life Sciences, Ann Arbor, MI, USA), into an HPLC amber vial. The filter was then rinsed with $100 \mu \mathrm{L}$ of MTBE:MeOH, to reduce possible losses of carotenoids to the filter membrane, which was combined with the previous filtered sample, to a total volume of $600 \mu \mathrm{L}$.

\section{HPLC analysis}

Carotenoids were separated on an Agilent 1260 Infinity Preparative HPLC instrument (Agilent Technologies, De Kleetlaan Belgium) by gradient elution with (A) water:MeOH (60:40) with $30 \mathrm{mM}$ of ammonium acetate, and (B) ACN:DCM (85:15), passing through an Accucore AM $^{\mathrm{TM}}$ C30 column $(2.6 \mu \mathrm{m}$ particle size, $100 \mathrm{~mm}$ length, $3 \mathrm{~mm}$ diameter, from Thermo Fisher Scientific) at $30^{\circ} \mathrm{C}, 10 \mu \mathrm{L}$ injection volume. Elution gradient was as follows: 0 min, $48 \% \mathrm{~B} ; 4$ $\min , 48 \%$ B; $5 \min , 52 \%$ B; $11 \min , 52 \%$ B; $13 \min , 75 \%$ B; $18 \min , 90 \%$ B; $35 \min , 90 \%$ B; 36min, 42\% B. Carotenoids were detected with a UV/VIS photodiode array detector, and identified according to their retention times and spectral data, based on the comparison to the 
corresponding individual standard. All peaks were integrated manually at $286 \mathrm{~nm}$ (phytoene), $350 \mathrm{~nm}$ (phytofluene), $440 \mathrm{~nm}$ (neoxanthin and violaxanthin), $450 \mathrm{~nm}$ (lutein and $\alpha$-carotene), $455 \mathrm{~nm}$ ( $\beta$-carotene, $\beta$-cryptoxanthin and IS), and at $470 \mathrm{~nm}$ (lycopene), according to each carotenoid's absorption maxima. Quantification was done using the internal standard method ${ }^{32}$.

\section{Surface tension and macroviscosity analysis}

To investigate if the addition of divalent minerals affected the physico-chemical characteristics of the digesta, we measured the surface tension and macroviscosity of the aqueous micellar fractions of the digesta. Macroviscosity was determined by measuring the steady state shear flow of the samples in an Anton-Paar rheometer (MCR 302, WESP, Graz, Austria), using a double gap concentric cylinder geometry (DG 26.7). Measurements were carried out by applying an upward-downward ramp shear stress range from 0.1 to $200 \mathrm{~s}^{-1}$, with a $60 \mathrm{~s}$ according to the Ostwald-de Waele model:

(1) $\tau=K \dot{\gamma}^{n}$

where: $\tau_{0}=$ the yield stress $(\mathrm{Pa}), K=$ consistency coefficient $\left(\mathrm{mPa} * \mathrm{~s}^{-\mathrm{n}}\right)$ and $n=$ rheological behavior index (dimensionless). All measurements were performed at $25 \pm 0.03{ }^{\circ} \mathrm{C}$. Surface tension of digesta samples, pre-conditioned at $25 \pm 0.1{ }^{\circ} \mathrm{C}$, were determined via the weightdrop method as previously described ${ }^{33}$ by Permprasert \& Devahastin (2005). The air-water interfacial properties of digesta were calculated as follows ${ }^{34}$ :

(2) $\sigma_{\text {digesta }}=\frac{m_{\text {digesta }}}{m_{\mathrm{H} 2 \mathrm{O}}} \times \sigma_{\mathrm{H} 2 \mathrm{O}}$ 
249 An aliquot of the aqueous micellar fraction was taken for the analysis of the micelle size and zeta potential (assumed to modulate the stability of the particles in solution). Aliquots were filtered beforehand, through a $0.2 \mu \mathrm{m}$ syringe filter. The intensity-weighted mean hydrodynamic radius and zeta-potential were determined by dynamic light scattering, and Laser Doppler Micro-electrophoresis respectively. Measurements were done at room temperature with a Zetasizer Nano Zs (Malvern Instruments, Malvern, UK).

\section{Statistical analysis}

Unless described otherwise, all values are given as mean \pm SD. Normality of distribution and equality of variance of the data were tested by normality plots and box plots, respectively. If required, log-transformation was conducted. All bioaccessibility data was normalised to a respective control which was run for every set of analyses. Bioaccessibility itself was calculated as the amount recovered in the final micellar phase compared to the original matrix content. A general linear model was developed to test the effect of minerals and their concentration on bioaccessibility, with concentration, matrix, type of mineral and carotenoid (total carotenoids for comparison across matrices, individual carotenoids to compare withinmatrix effects) as fixed factors, and fractional bioaccessibility as the dependent (observed) parameter. A P-value below 0.05 (2-sided) was considered statistically significant. Following significant Fisher F-values, Bonferroni’s post hoc-tests were conducted.

\section{RESULTS}

\section{Carotenoid profile of the food matrices}

271 In terms of total carotenoid content ( $\mu \mathrm{g} / \mathrm{g}$ wet weight of matrix), frozen spinach contained the highest amount, followed by tomato juice, carrot juice, field salad, and finally, apricot nectar (Table I). 
In the green leafy matrices (spinach and field salad), the xanthophylls (lutein, violaxanthin and neoxanthin) were the major carotenoids, representing $94 \%$ and $88 \%$ of the determined total carotenoid content, respectively, which is rather high compared to earlier studies ${ }^{35}$, due to the rather low $\beta$-carotene content found in the samples. In the case of the carrot and tomato juices and apricot nectar, carotenes ( $\beta$ - and $\alpha$-carotene, and lycopene) were the major carotenoids, with only a very small contribution from lutein. Also, all the three latter matrices were rich in the colourless carotenoids phytoene and phytofluene, which were not detected in green leafy varieties. The contribution of phytofluene and phytoene to the total quantified carotenoid content was $34 \%$ in carrot juice, $46 \%$ in tomato juice and $83 \%$ in apricot nectar.

\section{Bioaccessibility of total carotenoids across matrices}

The bioaccessibility of total carotenoids was significantly different $(p<0.001)$ between most matrices, except for apricot nectar and tomato juice. Bioaccessibility of total carotenoids was higher from the juices than it was from the green leafy varieties (Figure 1) and followed the order: apricot nectar $(21.4 \%)>$ tomato juice $(20.1 \%)>$ carrot juice $(17.1 \%)>$ field salad $(9.7 \%)$ $>\operatorname{spinach}(5.2 \%)$

Another aspect we observed was the remarkable bioaccessibility of phytofluene and phytoene of $18.5-46.9 \%$ and $21.1-47.6 \%$, respectively (Supplementary Table I), and their large contribution to average total carotenoid bioaccessibility in the juices and nectar (Fig. 1). This was especially evident in the case of tomato juice, where phytofluene and phytoene together represented $91.5 \%$ of the total bioaccessible fraction, while in the original matrix they made up $46.2 \%$ of the total carotenoid content.

\section{Bioaccessibility of $\beta$-carotene: effect of divalent minerals across different matrices}

Beta-carotene was the only carotenoid detectable in all of the 5 investigated matrices, thus it served as a reference carotenoid to compare the effect of the minerals across all tested matrices. 
300 Bioaccessibility of $\beta$-carotene was significantly affected $(\mathrm{p}<0.001)$ by the divalent minerals in a concentration-dependent fashion (Figure 2). Addition of magnesium led to a significant decrease of its bioaccessibility in all matrices. The addition of $200 \mathrm{mg} / \mathrm{L}$ magnesium to the test meals reduced the bioaccessibility of $\beta$-carotene by more than half (compared to the control), while at $300 \mathrm{mg}$ of magnesium, no more $\beta$-carotene was found in the micellar fraction (except for spinach). Similarly, a higher concentration of calcium, i.e. $1000 \mathrm{mg} / \mathrm{L}$, also reduced the bioaccessibility of $\beta$-carotene up to $100 \%$ for all tested matrices.

Interestingly, the addition of sodium had an overall significant positive effect on the bioaccessibility, especially in the case of $\beta$-carotene from the juices and apricot nectar, while for the green leafy varieties the effect was less pronounced (field salad) or inexistent (spinach).

310 Regarding zinc, its presence significantly improved $\beta$-carotene bioaccessibility from field salad and spinach for all concentrations tested, and in carrot juice for a concentration range between 12.5 and $50 \mathrm{mg} / \mathrm{L}$. On the other hand, at higher concentrations $(\geq 100 \mathrm{mg} / \mathrm{L})$, the presence of zinc significantly decreased $\beta$-carotene bioaccessibility from apricot nectar and tomato juice (up to $43 \%$ ), and up to $100 \%$ in carrot juice.

Comparison of the bioaccessibility of carotenes, xanthophylls, and colourless

319 bioaccessibility of the carotene $\beta$-carotene, as a function of varying concentrations of the investigated minerals, were compared to those of the xanthophylls lutein and neoxanthin, from either spinach or field salad (Figure 3, supplementary Table $\mathrm{X}$ for bioaccessibility values). The statistical interaction "matrix * mineral" had a significant $(\mathrm{P}<0.001)$ effect on the bioaccessibility of carotenoids. 
324 Carotenoids from spinach were overall less affected by the addition of minerals, than those 325 from field salad. Sodium and zinc had no statistically significant effect on the bioaccessibility

326 of xanthophylls measured in spinach test meals, while $\beta$-carotene bioaccessibility increased 327 significantly in the presence of zinc (> $12.5 \mathrm{mg} / \mathrm{L}$, Figure 2$)$. As for field salad, zinc improved 328 significantly $(\mathrm{P}<0.001)$ the bioaccessibility of both lutein, neoxanthin and $\beta$-carotene, by up to $39 \%, 31 \%$, and $63 \%$, respectively.

330 Addition of sodium to the field salad test meals led to a significant $(\mathrm{P}<0.05)$ increase in lutein and $\beta$-carotene bioaccessibility, by ca. $4 \%$ and $31 \%$, respectively, at a concentration of 350 $\mathrm{mg} / \mathrm{L}$. At highest concentrations (750 mg/L and $1500 \mathrm{mg} / \mathrm{L}$ ), bioaccessibility of xanthophylls, but not that of $\beta$-carotene, was significantly reduced (up to $35 \%$ ).

334 Also for magnesium, the bioaccessibility of carotenoids from spinach appeared less strongly affected than from field salad. The significant effects were seen $>300 \mathrm{mg} / \mathrm{L}$ for spinach samples and $>100 \mathrm{mg} / \mathrm{L}$ in field salad samples. Addition of calcium at a concentration of $250 \mathrm{mg} / \mathrm{L}$ improved significantly the amount of lutein (ca. 13\%) and neoxanthin (ca. 24\%) recovered in the micellar fraction from field salad test meals, followed by a significant $(\mathrm{P}<0.001)$ reduction $(>500 \mathrm{mg} / \mathrm{L})$.

Differences between lycopene and phytoene and phytofluene. Despite their similar molecular structure, the bioaccessibility of lycopene was significantly lower $(\mathrm{P}<0.001)$ than that of phytoene and phytofluene, from tomato juice samples. Under control conditions (i.e. no additional mineral), the average bioaccessibility of lycopene from tomato juice was of $2.9 \pm 1.8 \%$, compared to $49.0 \pm 14.5 \%$ and $53.6 \pm 24.4 \%$ for phytoene and phytofluene, 346 respectively.

347 Concerning the response of these carotenoids to the added minerals (Figure 4), the patterns of 348 bioaccessibility variations between these three carotenoids were similar in the presence of 
additional sodium and magnesium. Adding magnesium at $>100 \mathrm{mg} / \mathrm{L}$ to the tomato juice digesta decreased $(\mathrm{P}<0.001)$ bioaccessibility of all three carotenoids, and at $300 \mathrm{mg} / \mathrm{L}$ the bioaccessibility dropped close to zero. Sodium, at $750 \mathrm{mg} / \mathrm{L}$ significantly $(\mathrm{P}<0.001)$ enhanced the bioaccessibility of phytoene and phytofluene; at $1500 \mathrm{mg} / \mathrm{L}$ the bioaccessibility of all three carotenoids significantly improved by $87 \%$ for lycopene, $118 \%$ for phytoene and $148 \%$ for phytofluene. Adding $250 \mathrm{mg} / \mathrm{L}$ of calcium increased the recovery of phytoene and phytofluene in the micellar fraction by $18 \%$ and $22 \%$, while it had no significant effect on lycopene. Similarly to other carotenoids, $500 \mathrm{mg} / \mathrm{L}$ calcium reduced the bioaccessibility by more than (Figure 4).

\section{Effect of divalent minerals on the physico-chemical properties of the digesta}

Effect of mineral addition on the zeta-potential of the digesta. To verify the presence of mixed micelles in the micellar fraction of digesta and to evaluate the stability of the particles in solution, we attempted to measure micelle size as well as the zeta potential. However, due to time and cost reasons, measurements were performed only for spinach and carrot juice samples. Unfortunately, micelle size results were not informative. As measurements were not done in situ and had to be shipped, micellar fractions had to be previously frozen and thawed on the day of the analysis. The temperature changes might have caused particle size variations, making it impossible to accurately measure the micelle size distribution of the micellar fraction of the digesta.

The average zeta-potential value of the micellar fraction of the spinach and carrot juice digesta, under control conditions (i.e. no added mineral, $\mathrm{C}=0 \mathrm{mg} / \mathrm{L}$ ) was of $-30.9 \pm 2.4 \mathrm{mV}$ and -30.6 
$\pm 9.6 \mathrm{mV}$, respectively. Variations of the zeta potential of the micellar fractions, depended on the type of mineral and concentration (Figure 5 and 6). While zinc and sodium did not cause visible variations in the zeta-potential, a more obvious variation was seen for calcium and magnesium. As the concentrations of the divalent minerals increased, the zeta-potential tended towards zero (Fig 5 and Fig 6), especially in the case of calcium and magnesium, suggesting that the colloid became unstable. Lowest zeta-potential values $(-2.53 \mathrm{mV})$ were observed for spinach samples digested with calcium (at $1000 \mathrm{mg} / \mathrm{L}$ ).

\section{Effect of divalent minerals on the macroviscosity and surface tension of the digesta. In}

general, the digesta were prevalently characterised by a Newtonian fluid behaviour, with digesta from tomato, spinach and field salad exerting the lowest macroviscosities $(0.97-1.02$ $\mathrm{mPa} \cdot \mathrm{s})$. Significantly $(\mathrm{P}<0.01)$ higher macroviscosity values were recorded in the case of carrot juice (ca. $1.08 \mathrm{mPa} \cdot \mathrm{s})$ and apricot nectar $(2.16 \mathrm{mPa} \cdot \mathrm{s})$. It should be noted that in the latter case, the digesta exhibited a rather pseudoplastic (shear thinning) behaviour, suggesting the presence of a loosely structured/thickened bulk phase. Regarding sodium addition, the digesta macroviscosities exerted a slight increase (up to 4\%), as a result of its buffering role to the biopolymers' hydrodynamic radii. In the presence of divalent minerals, a significant decrease of the digesta macroviscosity was detected. This was steeper for the high pectin content systems i.e. apricot, tomato and carrot juice. Contrary to calcium containing digesta, the apricot nectar - magnesium or zinc digesta exerted a distinct macroviscosity inflection point at low mineral concentrations, followed by a steep decrease upon further mineral content increase. In the case of leafy vegetable matrices, macroviscosity was also adversely affected by the presence of divalent minerals, but to a much lesser extent.

As for surface tension (Fig. 7e-h), the cationic mineral species present in the intestinal chymes, and to a lesser extent, the type of the food matrix, substantially impacted the air-water 
interfacial properties. Surface tension for control digesta systems ranged from ca. 36.2 (for apricot nectar and carrot juice) to $37.5 \mathrm{dyn} / \mathrm{cm}$ (for tomato, spinach and field salad) showing a moderate negative $(\mathrm{r}=-0.74, \mathrm{P}<0.05)$ correlation to the macroviscosity data. In the presence of the divalent cationic species, surface tension increased by 5 to $30 \%$, depending on the digested food matrix, with field salad and spinach based digesta exerting the highest depletion in surface active compounds. Apricot nectar and carrot juice obtained digesta experienced a rather moderate increase of surface tension.

\section{DISCUSSION}

In the present study, we investigated the interaction of divalent minerals with carotenoids from various food matrices during simulated gastro-intestinal digestion. Previously, we found that the presence of calcium and magnesium, at varying concentrations, had the ability to significantly decrease the amount of isolated carotenoids (in absence of a food matrix), present in the micellar fraction of the digesta ${ }^{23}$. The different food matrices chosen in the present study represented regularly consumed fruits and vegetables, providing the most common dietary carotenoids $^{35}$ : $\beta$-carotene and $\alpha$-carotene, lycopene, and lutein. Two additional regularly consumed carotenoids investigated were the colourless carotenoids phytoene and phytofluene. Although they are less commonly reported, they are present at relatively high concentrations in a broad spectrum of fruits and vegetables, including apricot, carrot and tomato ${ }^{35}$. Carotenoid bioaccessibility was reduced significantly in all matrices by the highest concentrations of magnesium and calcium studied, to almost zero. This is similar to what has been reported earlier by Biehler et al $(2011)^{24}$, investigating micellarization of spinach-borne carotenoids digested with calcium, magnesium and iron. However, the influence of the matrix was apparent when evaluating the effects of divalent minerals on the bioaccessibility of carotenoids. Responses to divalent minerals appeared to differ between green leafy matrices 
and the juices. Increasing concentrations of calcium and magnesium generally resulted in reduced bioaccessibility of carotenoids following digestion. However, at lower concentrations (250 mg/L calcium, $100 \mathrm{mg} / \mathrm{L}$ magnesium), the bioaccessibility of carotenes, specifically $\beta$ carotene, was enhanced in juices and nectar, though neither in spinach nor field salad. Similarly, though employed as a control monovalent ion, sodium improved bioaccessibility in juices and apricot nectar, especially at higher concentrations ( $\geq 750 \mathrm{mg} / \mathrm{L})$, while lutein and neoxanthin bioaccessibility were significantly $(\mathrm{P}<0.05)$ reduced in field salad. It is possible that the more rigid cellular matrix of solid constituents, with carotenoids not yet present in lipid droplets at earlier phases of digestion, is less prone to interactions with divalent cations, but this remains speculative.

The negative effects of the divalent cations at higher concentrations were correlated with increased surface tension, suggesting the depletion of surfactants (bile salts) from the system, similar as observed earlier for carotenoids in systems without food matrix ${ }^{23}$. The fact that macroviscosity in parallel decreased, towards values similar to that of pure water, also suggested removal of soluble compounds from the system by flocculation, as observed also visually. Depletion of carotenoids is likely to occur as a consequence of the binding of divalent cations to unconjugated bile acids ${ }^{36}$ and free fatty acids, forming bile salts of poor solubility and insoluble fatty acids soaps ${ }^{25,37,38}$, resulting in precipitation. This precipitation was visible at the end of the digestion, when compared to control conditions (no minerals added). Without the presence of bile acids, or free fatty acids, stimulating the formation of mixed-micelles, bioaccessibility of carotenoids is expected to be drastically reduced. Similarly, sodium can also interact with bile acids, resulting in higher solubility of the bile salts, and lower critical micelle concentrations, promoting mixed-micelle formation ${ }^{28}$ and thus bioaccessibility of carotenoids, explaining the higher recovery from the aqueous micellar fraction of the digesta with added sodium. 
449 The observed positive effects of divalent minerals at lower concentrations on bioaccessibility 450 are more challenging to explain, but could include lipolysis. Lipolysis occurs via the adsorption 451 of pancreatic lipase to the surface of lipid droplets. As lipid digestion proceeds and the products 452 of lipolysis (e.g. free fatty acids) build up at the interface, lipase activity is inhibited. In order 453 for lipolysis to proceed, fatty acids and other molecules adsorbed to the surface of lipids (e.g. 454 proteins and soluble fibres) need to be displaced ${ }^{39}$. This would occur with increasing cation concentrations, precipitating the products, allowing for continuous lipase activity, aiding in the transferral of lipid droplets to mixed micelles and fostering carotenoid release from lipid droplets. Calcium and other divalent cations also have the ability to cross-link proteins ${ }^{40}$ and soluble fibres ${ }^{41,42}$, perhaps removing some factors that could negatively affect carotenoid bioaccessibility.

Concerning differences in carotenoid bioaccessibility between matrices, spinach contained the highest amount of total carotenoids, followed by tomato juice, carrot juice, field salad, and finally apricot nectar. Nevertheless, all tested matrices had a unique carotenoid profile, and apart from $\beta$-carotene, no other carotenoid was commonly measured across all the five matrices. The investigated spinach and field salad had similar carotenoid composition as previously reported for other green leafy vegetables, containing $\beta$-carotene, lutein, violaxanthin and neoxanthin ${ }^{43}$, with $90 \%$ of total carotenoids constituted by xanthophylls (lutein, violaxanthin and neoxanthin). In contrast, xanthophylls accounted for less than $1 \%$ of the total carotenoid content determined for the juices and apricot nectar.

Despite the fact that spinach and field salad contained mainly xanthophylls, reported as being more bioaccessible than carotenes ${ }^{23,44,45}$, their average total carotenoid bioaccessibility was significantly lower than that of the juices and nectar. This could have been the result of different storage form of carotenoids in plant tissues ${ }^{43}$ - chromoplasts (for carrot and tomato) vs. 473 chloroplast pigment-protein complexes (spinach and field salad) ${ }^{19,46,47}$ and other matrix 
constituents such as dietary fiber ${ }^{48}$. Furthermore, food processing ${ }^{13}$ and different methods of disruption of the cell matrix also impact the release of carotenoids. Juicing of carrots has been shown to improve the bioaccessibility of carotenoids from the food matrix ${ }^{46}$ compared to raw carrots, as a result of cell rupture, making carotenoids more accessible.

Phytoene and phytofluene were present in the tested juices and apricot nectar, where they contributed at least to a third to the total carotenoid content. Despite their high contribution to total carotenoid content of many different fruits and vegetables ${ }^{35}$, their appearance in blood plasma $^{49}$, and reported bioactive aspects such as anti-oxidant activity ${ }^{50}$, not much information is available on bioavailability aspects, including bioaccessibility. In the present investigation, phytoene and phytofluene fractional bioaccessibilities were surprisingly high, between $27 \%$ and $70 \%$. Bioaccessibility nonetheless depended on the type of matrix. Carrot juice showed a significantly lower bioaccessibility of these colourless carotenoids than tomato juice and apricot nectar, while apricot nectar digestion resulted in significantly higher phytoene and phytofluene bioaccessibility, compared to the other two matrices. These results are in line with those found in a previous study ${ }^{51}$. Despite being similar to lycopene in its molecular structure, very different bioaccessibilities were encountered. Meléndez-Martínez et al. (2015) suggested that the number of conjugated double bonds (cDB) influences the shape of the molecule. Its high number in lycopene $(11 \mathrm{cDB})$ would prevent molecule folding, while phytoene $(3 \mathrm{cDB})$ and phytofluene $(5 \mathrm{cDB})$ bonds are able to rotate more freely, assuming less rigid shapes. This could facilitate the incorporation of the colourless carotenoids into mixed micelles, explaining their higher bioaccessibility. Similarly, another study reported higher bioaccessibility of phytoene, from different food matrices, compared to $\beta$-carotene and even lutein, including in carrots and tomatoes ${ }^{19}$. Contrarily, phytoene bioaccessibility was comparable to that of $\beta$ carotene from orange pulp and juice, perhaps due to the low amount of $\beta$-carotene present in those matrices, facilitating its solublity ${ }^{52}$. 
499 Regarding physicochemical properties, the higher macroviscosity of the apricot juice was

500 likely due to the high content of pectin and/or due to higher total solids (>14\% w/w) and sugar content $(>13 \% \mathrm{w} / \mathrm{w})$, promoting viscosity via decreasing the hydrodynamic free volume

502 between the biopolymer molecules, triggering hydrophobic interaction or hydrogen bonding of

503 side chain segments. In case of leafy vegetable matrices, their very low viscosimetric responsiveness is likely to be attributed to their higher content in insoluble fibre, compared to juices $^{53}$. Regardless of the food matrix, it is assumed that the observed macroviscosity reduction with increasing divalent mineral concentration was mainly induced by the precipitation of bile salt matter, depleting total solids. The rheological behaviour of the digesta were diverse, with apricot nectar - magnesium or zinc binary systems undergoing structure conformational changes as suggested by the observed rheological behaviour transitions, e.g. pseudoplastic to Newtonian. The inflection point for apricot digesta containing magnesium or zinc is also likely explained by its pectin content. It is well established that pectins (depending on their methyl ester content) may undergo electrostatic interactions (via the egg-box structure conformation) with divalent cations, exerting a selective chemical affinity (for polygalacturonic segments) following the order: calcium $>$ zinc $>$ magnesium ${ }^{54}$. This implies that electrostatic bridging of calcium with pectins can be triggered at much lower concentrations compared to the other two cations. This would explain the absence of the inflection point in the case of apricot nectar - calcium digesta samples. Upon increasing the cation concentration, an antagonistic ion binding action between bile salts and polygalacturonic segment occurs, with the latter being disfavoured, inducing a strong precipitation. As for surface tension, it is hypothesised that the bile salt binding capacity antagonism between divalent cations and pectins played a buffering role on aggregative depletion phenomena. The amount of soluble pectin in the bulk phase appeared to be well corroborating the average 
depletion of surfactants i.e. $9 \%$ (magnesium) to $16 \%$ (calcium) for carrot juice and apricot nectar and $20 \%$ (magnesium) to $26 \%$ (calcium) for tomato juice, spinach and field salad.

\section{CONCLUSIONS}

527

Bioaccessibility of different carotenoids, from different matrices, was affected negatively by divalent mineral cations, and this was mirrored by decreased macroviscosity, increased surface tension of the digesta, as well as by the decrease of the absolute zeta-potential of the mixed micelles. Interestingly, the colourless carotenoids phytoene and phytofluene, displayed a bioaccessibility higher than those obtained for other carotenes. However, the outcomes of the influence of divalent cations on bioaccessibility appear as a result of a complex interaction between matrix, type of carotenoids and minerals and their concentration. Interestingly, concentrations of divalent minerals, much below the equivalent to the RDA for calcium and magnesium, appeared to improve bioaccessibility of carotenoids, likely by acting synergistically with bile acids, possibly promoting lipolysis. The results presented could be relevant regarding the intake and dosage of food supplements, specifically when combining carotenoids with high divalent mineral doses. Further investigations in vivo, possibly also including other liposoluble dietary constituents are warranted to attest these observations.

\section{ACKNOWLEDGEMENTS}

The authors are grateful for the support of the Fonds National de la Recherche Luxembourg (Grant No. C11/SR/1268260). The help of Boris Untereiner with extractions and digestions, and of Cedric Guignard and Emmanuelle Coco for their help and advice regarding HPLC analyses, is greatly appreciated. 
5481 C. Stange and C. Flores, in Advances in Photosynthesis - Fundamental Aspects, ed. M. Najafpour, InTech, 2010, pp. $54977-96$.

5502 P. D. Fraser and P. M. Bramley, Prog. Lipid Res., 2004, 43, 228-65.

5513 B. Demmig-Adams, A. M. Gilmore and W. W. Adams III, FASEB J., 1996, 10, 403-412.

5524 G. Britton, FASEB J., 1995, 9, 1551-1558.

5535 A. Kaulmann and T. Bohn, Nutr. Res., 2014, 34, 907-29.

5546 N. I. Krinsky and E. J. Johnson, Mol. Aspects Med., 2005, 26, 459-516.

$5557 \quad$ N. K. Scripsema, D. Hu and R. B. Rosen, J. Ophthalmol., 2015, 2015, 1-13.

5568 S. Voutilainen, T. Nurmi, J. Mursu and T. H. Rissanen, Am. J. Clin. Nutr., 2006, 83, $1265-71$.

5579 L. Brazionis, K. Rowley, C. Itsiopoulos and K. O’Dea, Br. J. Nutr., 2009, 101, $270-7$.

$55810 \quad$ O. Kucuk, F. H. Sarkar, Z. Djuric, W. Sakr, M. N. Pollak, F. Khachik, M. Banerjee, J. S. Bertram and D. P. Wood, 559 Exp. Biol. Med. (Maywood)., 2002, 227, 881-5.

56011 G. a Sonn, W. Aronson and M. S. Litwin, Prostate Cancer Prostatic Dis., 2005, 8, 304-10.

$561 \quad 12 \quad$ J. J. Castenmiller and C. E. West, Annu. Rev. Nutr., 1998, 18, 19-38.

56213 K. van het Hof and C. West, J. Nutr., 2000, 103, 503-506.

56314 W. Stahl, H. Van Den Berg, J. Arthur, A. Bast, J. Dainty, R. M. Faulks, C. Gärtner, G. Haenen, P. Hollman, B.

564 Holst, F. J. Kelly, M. Cristina Polidori, C. Rice-Evans, S. Southon, T. Van Vliet, J. Viña-Ribes, G. Williamson and S. B. Astley, Mol. Aspects Med., 2002, 23, 39-100.

O. O’Connell, L. Ryan, L. O’Sullivan, S. A. Aherne-Bruce and N. M. O’Brien, Int. J. Vitam. Nutr. Res., 2008, 78, $238-246$.

H. Palafox-Carlos, J. F. Ayala-Zavala and G. a. González-Aguilar, J. Food Sci., 2011, 76, 6-15.

S. R. Goltz, W. W. Campbell, C. Chitchumroonchokchai, M. L. Failla and M. G. Ferruzzi, Mol. Nutr. Food Res., 2012, 56, 866-77. 

$2012,25,56-65$. 2015. 
614 Table I - Carotenoid content ( $\mu \mathrm{g} / \mathrm{g}$ food wet weight) for each of the tested food matrices.

\begin{tabular}{llccccccccc}
\hline Food matrix & Latin name & $\alpha$-Car & $\beta$-Car & Lyc & Lut & Vio & Neo & PTE & PTF & Total \\
\hline Apricot nectar & $\begin{array}{l}\text { Prunus } \\
\text { armeniaca }\end{array}$ & nd & 2.87 & nd & nd & nd & nd & 11.27 & 2.79 & 16.87 \\
Tomato juice & $\begin{array}{l}\text { Solanum } \\
\text { lycopersicum }\end{array}$ & nd & 2.98 & 85.04 & 0.31 & nd & nd & 65.09 & 8.20 & 158.6 \\
$\begin{array}{l}\text { Daucus } \\
\text { Carrot juice }\end{array}$ & 20.52 & 66.67 & nd & 1.24 & nd & nd & 40.44 & 4.33 & 133.2 \\
$\begin{array}{l}\text { Frozen } \\
\text { spinach }\end{array}$ & $\begin{array}{l}\text { Spinacia } \\
\text { oleracea }\end{array}$ & nd & 10.54 & nd & 100.1 & 64.80 & 16.26 & nd & nd & 191.7 \\
$\begin{array}{l}\text { Field Salad } \\
\begin{array}{l}\text { Valerianella } \\
\text { locusta }\end{array}\end{array}$ & nd & 14.79 & nd & 69.80 & 30.92 & 15.06 & nd & nd & 130.6 \\
creamer & & nd & 21.55 & nd & nd & nd & nd & nd & nd & 21.55
\end{tabular}

(10\% fat)

$\alpha$-Car: $\alpha$-Carotene; $\beta$-Car: $\beta$-Carotene; Lyc: Lycopene; Lut: Lutein; Vio: Violaxanthin; Neo: Neoxanthin; PTE: Phytoene;

PTF: Phytofluene, nd: not detectable. All forms represent the more abundant carotenoids isomers (i.e. all-trans). Values are means of duplicate analysis. 
FIGURE HEADINGS

639 Figure 1. Average total carotenoid bioaccessibility (\%) between matrices. Each bar represents 640 the relative contribution of the individual carotenoids, detected in each matrix, to the 641 percentage of total carotenoids recovered in the bioaccessible fraction of the digesta, relative 642 to the total carotenoid amount present in the undigested test meal. Different letters represent 643 statistically significant differences $(\mathrm{P}<0.001)$. Total number of replicates was 16.

644 Figure 2. Effect of divalent cations and sodium on the bioaccessibility of $\beta$-carotene across 645 different food matrices. Food matrices were digested in the presence of varying concentrations 646 (mg/L) of 3 different divalent cations (calcium, zinc and magnesium) and of the monovalent cation (sodium). Bioaccessibility values are represented as the percentage of $\beta$-carotene recovered from the aqueous micellar fraction at the end of the in vitro GI digestion, compared to the amount of $\beta$-carotene present in the original matrix. Values represent mean $\pm \operatorname{SD}$ of $n=$ 4. Bars signalled with either * $(\mathrm{P}<0.05)$ or $* *(\mathrm{P}<0.01)$ were statistically different from the control condition, i.e. $[$ added mineral] $=0 \mathrm{mg} / \mathrm{L}$.

Figure 3. Graphical representation of trends in bioaccessibility variation of carotenoids from spinach and field salad, as effected by cationic minerals at different concentration ranges. Bars in dark and light grey represent the highest and lowest points, respectively, of the measured bioaccessibility. Concentration range is depicted as $\mathrm{C} 0$ to $\mathrm{C} 5$, corresponding to the following: Calcium $\mathrm{C} 0=0 \mathrm{mg} / \mathrm{L} ; \mathrm{C} 1=250 \mathrm{mg} / \mathrm{L} ; \mathrm{C} 2=500 \mathrm{mg} / \mathrm{L} ; \mathrm{C} 3=1000 \mathrm{mg} / \mathrm{L}$. Sodium $\mathrm{C} 0=0$ $\mathrm{mg} / \mathrm{L} ; \mathrm{C} 1=375$ mg/L; C2 = $750 \mathrm{mg} / \mathrm{L} ; \mathrm{C} 3=1500 \mathrm{mg} / \mathrm{L}$. Magnesium C0 = 0 mg/L; C1 = 100 $\mathrm{mg} / \mathrm{L} ; \mathrm{C} 2=200 \mathrm{mg} / \mathrm{L} ; \mathrm{C} 3=300 \mathrm{mg} / \mathrm{L}$. Zinc C0 $=0$ mg/L; C1 $=12.5 \mathrm{mg} / \mathrm{L} ; \mathrm{C} 2=25 \mathrm{mg} / \mathrm{L} ; \mathrm{C} 3$

$659=50 \mathrm{mg} / \mathrm{L} ; \mathrm{C} 4=100 \mathrm{mg} / \mathrm{L} ; \mathrm{C} 5=200 \mathrm{mg} / \mathrm{L}$. Symbol $*$ above bar indicates statistical significance $(\mathrm{P}<0.05)$, compared to controls (no mineral added). 
661 Figure 4. Graphical representation of the trends in bioaccessibility variation of lycopene and 662 the colourless carotenoids, phytoene and phytofluene, from tomato juice, as an effect of cations 663 at different concentration ranges. Bars in dark and light grey represent the highest and lowest 664 points, respectively, of the measured bioaccessibility. Concentration range is depicted as C0 to $665 \mathrm{C} 5$, which correspond to the following values: Calcium $\mathrm{C} 0=0 \mathrm{mg} / \mathrm{L} ; \mathrm{C} 1=250 \mathrm{mg} / \mathrm{L} ; \mathrm{C} 2=$ $666500 \mathrm{mg} / \mathrm{L} ; \quad \mathrm{C} 3=1000 \mathrm{mg} / \mathrm{L}$. Sodium C0 = $0 \mathrm{mg} / \mathrm{L} ; \mathrm{C} 1=375 \mathrm{mg} / \mathrm{L} ; \mathrm{C} 2=750 \mathrm{mg} / \mathrm{L} ; \mathrm{C} 3=$ 6671500 mg/L. Magnesium C0 = 0 mg/L; C1 = 100 mg/L; C2 = 200 mg/L; C3 = 300 mg/L. Zinc $\mathrm{C} 0=0 \mathrm{mg} / \mathrm{L} ; \mathrm{C} 1=12.5 \mathrm{mg} / \mathrm{L} ; \mathrm{C} 2=25 \mathrm{mg} / \mathrm{L} ; \mathrm{C} 3=50 \mathrm{mg} / \mathrm{L} ; \mathrm{C} 4=100 \mathrm{mg} / \mathrm{L} ; \mathrm{C} 5=200 \mathrm{mg} / \mathrm{L}$. 669 Symbol * above bar indicates statistical significance $(\mathrm{P}<0.05)$, compared to control (no mineral 670 added).

Figure 5. Average spinach-borne $\beta$-carotene bioaccessibility (\%), and absolute zeta-potential $672(\mathrm{mV})$ of spinach aqueous micellar fraction, after digestion with different cations at varying 673 concentrations. Bars represent bioaccessibility, while markers $\bullet$ represent the zeta potential. 674 A: Calcium; B: Sodium; C: Magnesium; D: Zinc. Error bars represent standard deviation of $n$ $675=4$ replicates.

676 Figure 6. Average carrot juice-borne $\beta$-carotene bioaccessibility (\%), and absolute zetapotential $(\mathrm{mV})$ of carrot juice aqueous micellar fraction, after digestion with different cations at varying concentrations. Bars represent bioaccessibility, while markers $\bullet$ represent the zetapotential. A: Calcium; B: Sodium; C: Magnesium; D: Zinc. Error bars represent standard 680 deviation of $\mathrm{n}=4$ replicates.

Figure 7. Normalised macroviscosity and surface tension values of the aqueous micellar 682 fractions of different food matrices after digestion with varying cationic mineral 683 concentrations. 


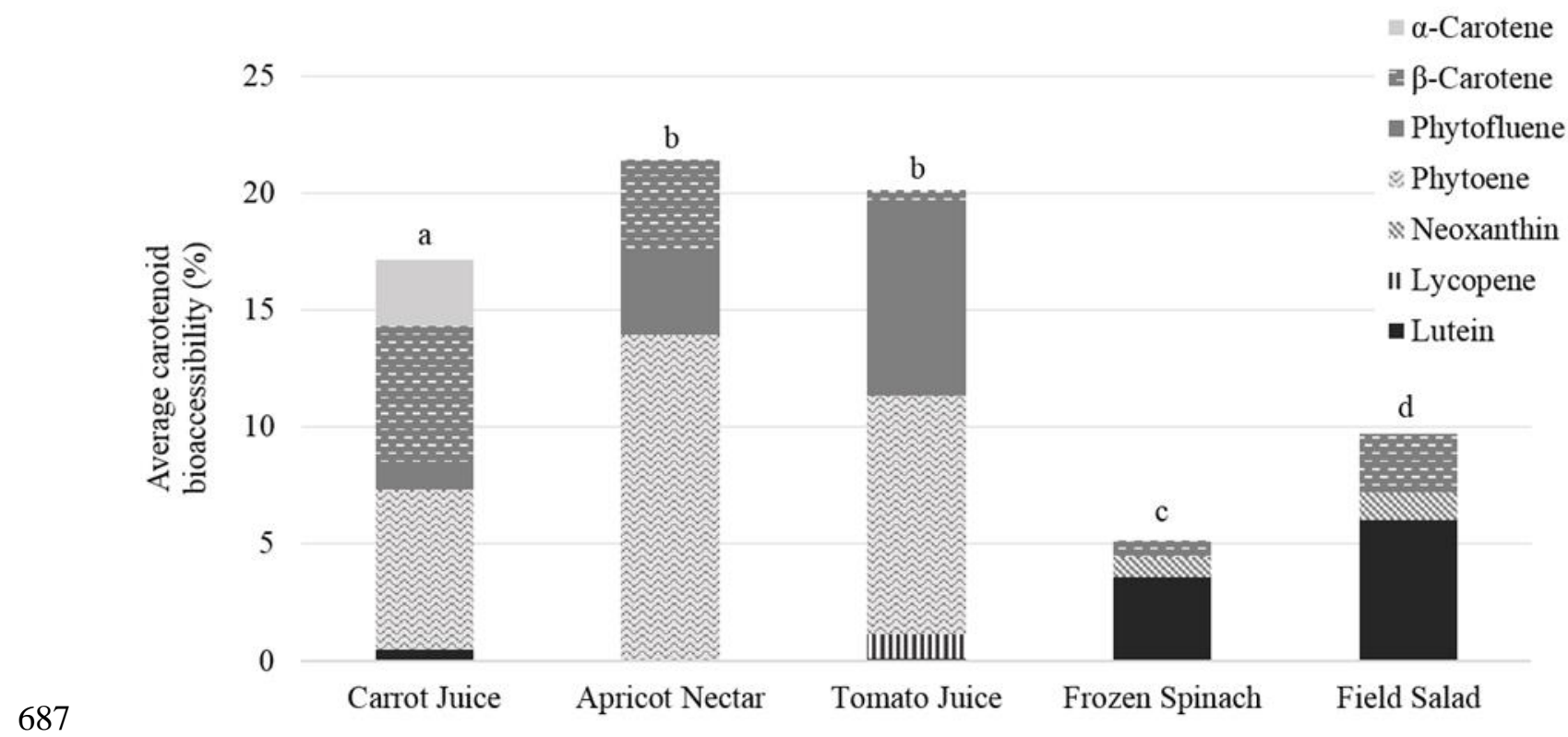

688

$689 \quad$ Figure 1

690 

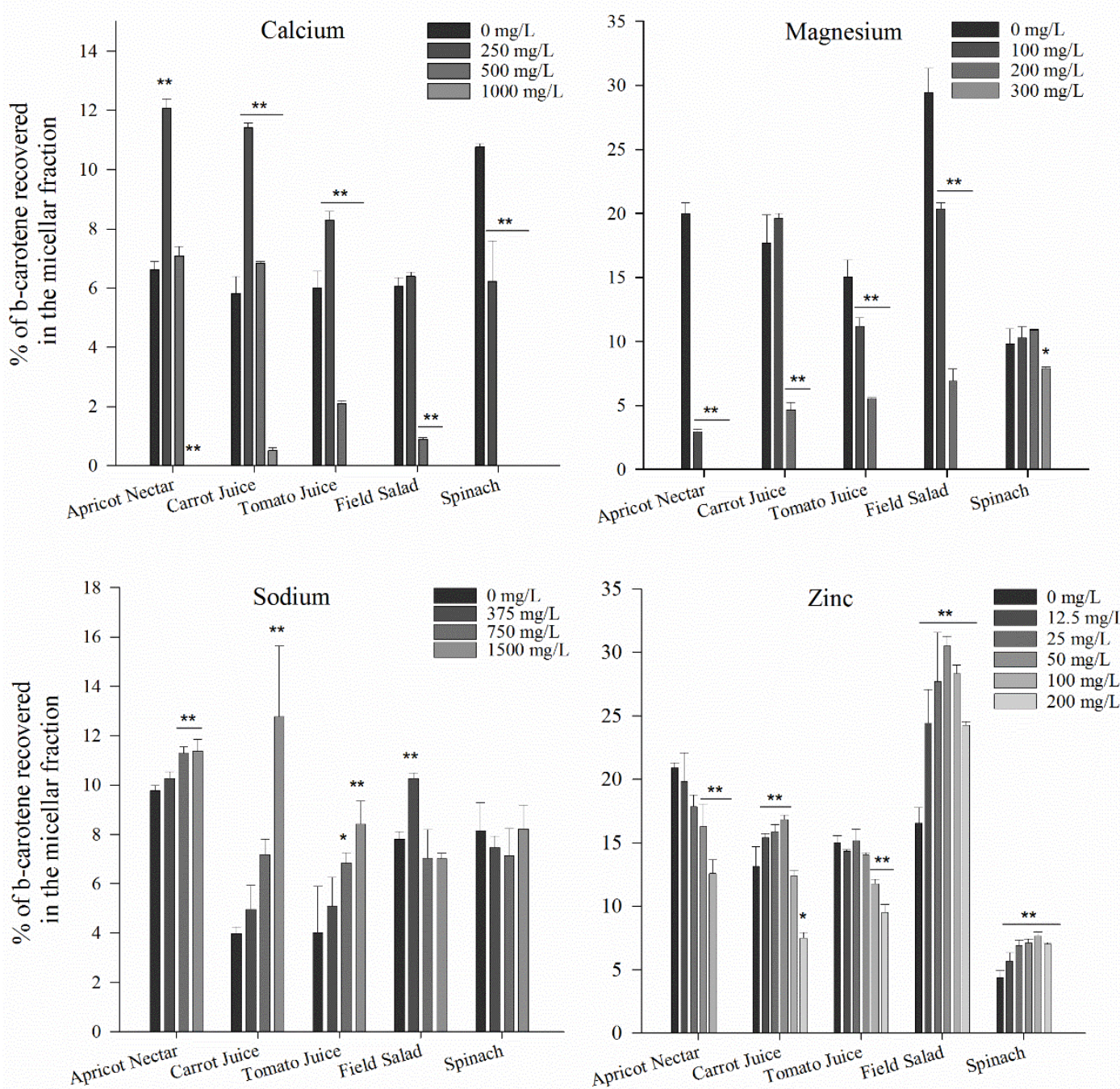

691

692

693

Figure 2

694 


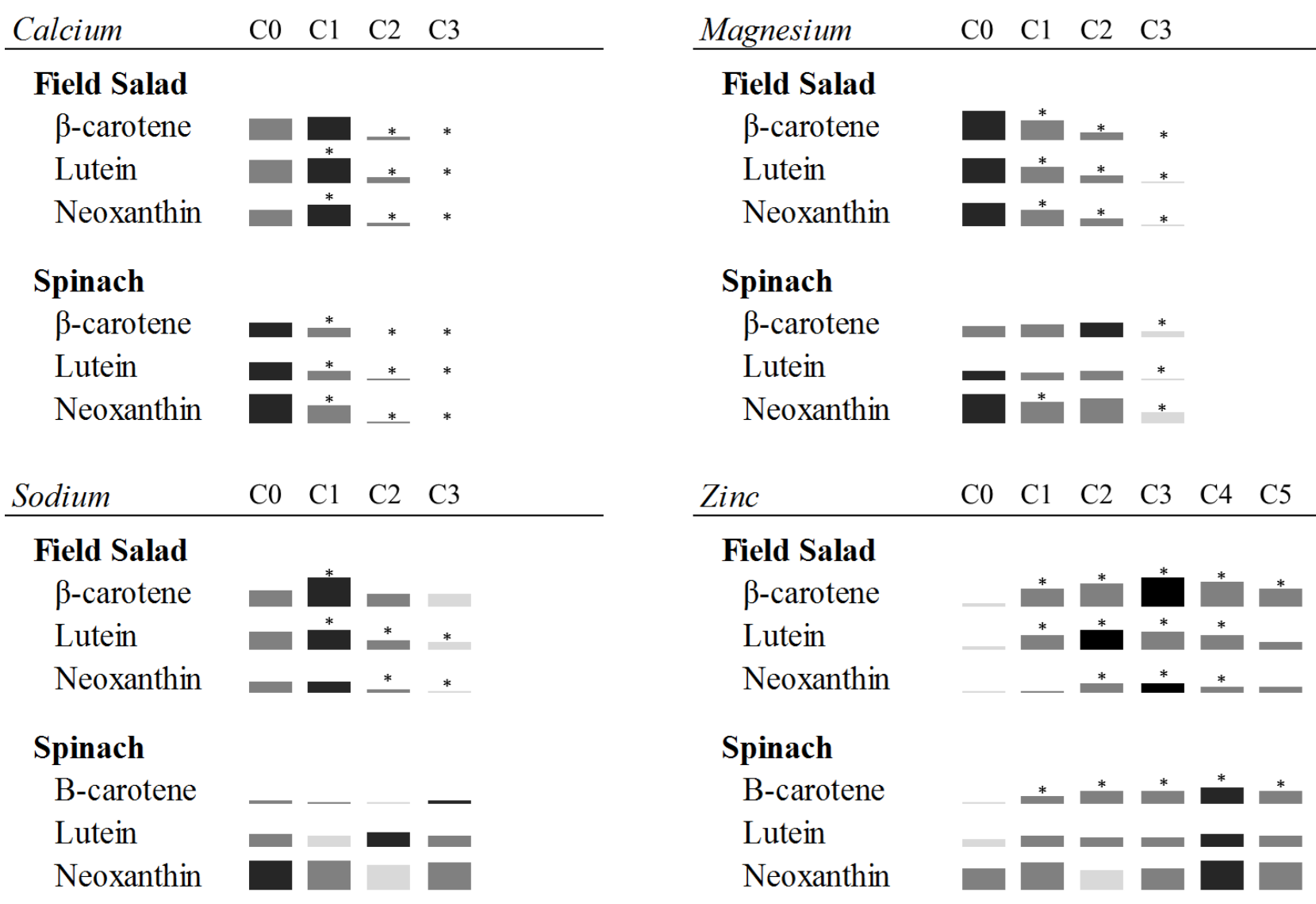

696

$697 \quad$ Figure 3 


\begin{tabular}{lllll} 
Calcium & C0 & C1 & C2 & C3 \\
\hline
\end{tabular}

\section{Tomato Juice}

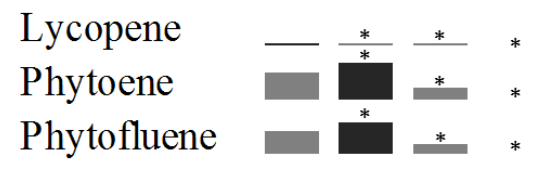

\begin{tabular}{lllll} 
Magnesium & C0 & C1 & C2 & C3 \\
\hline Tomato Juice & & & &
\end{tabular}

Lycopene

Phytoene

Phytofluene

699

700

701

Figure 4

702 

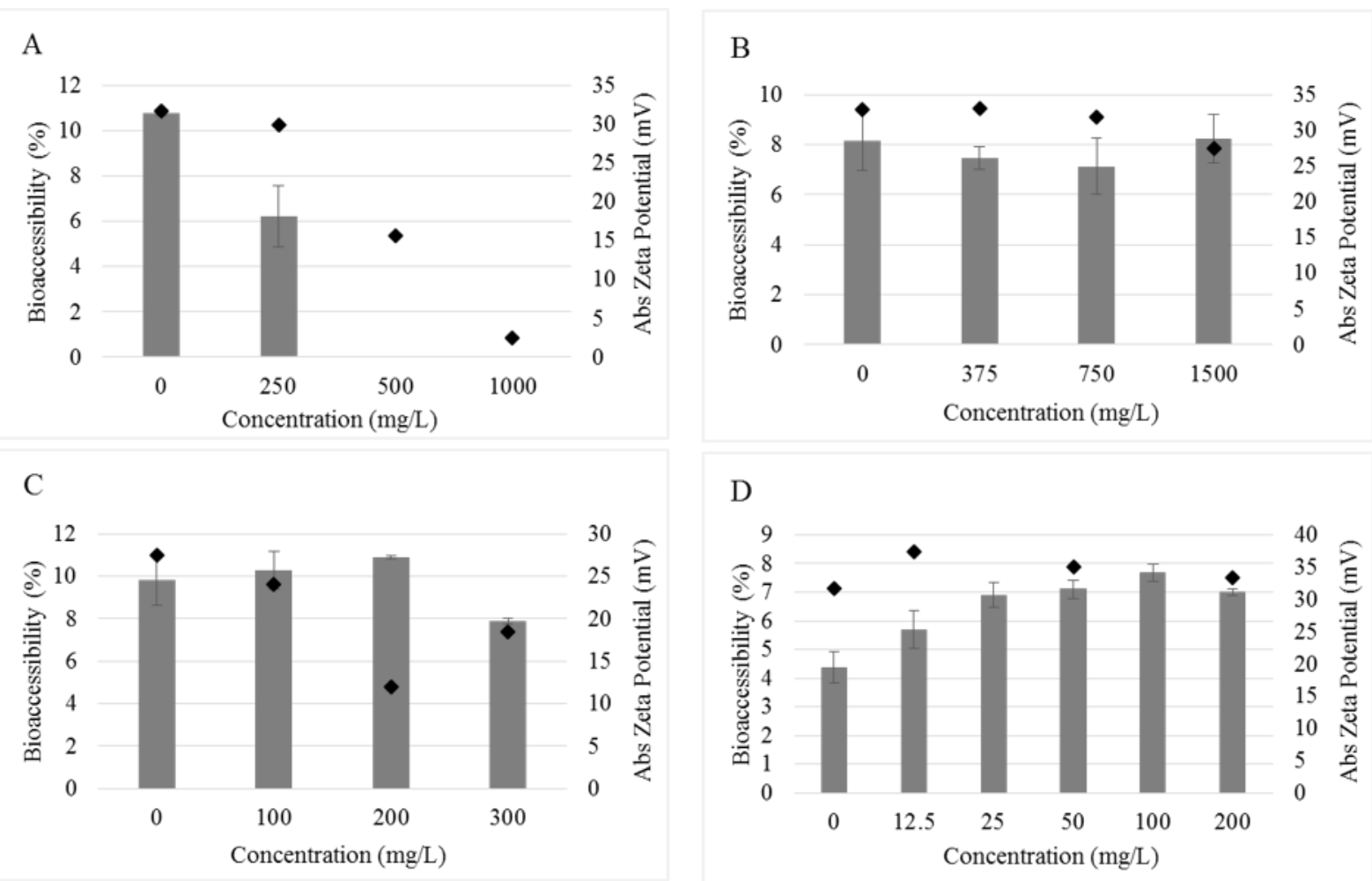

Figure 5 

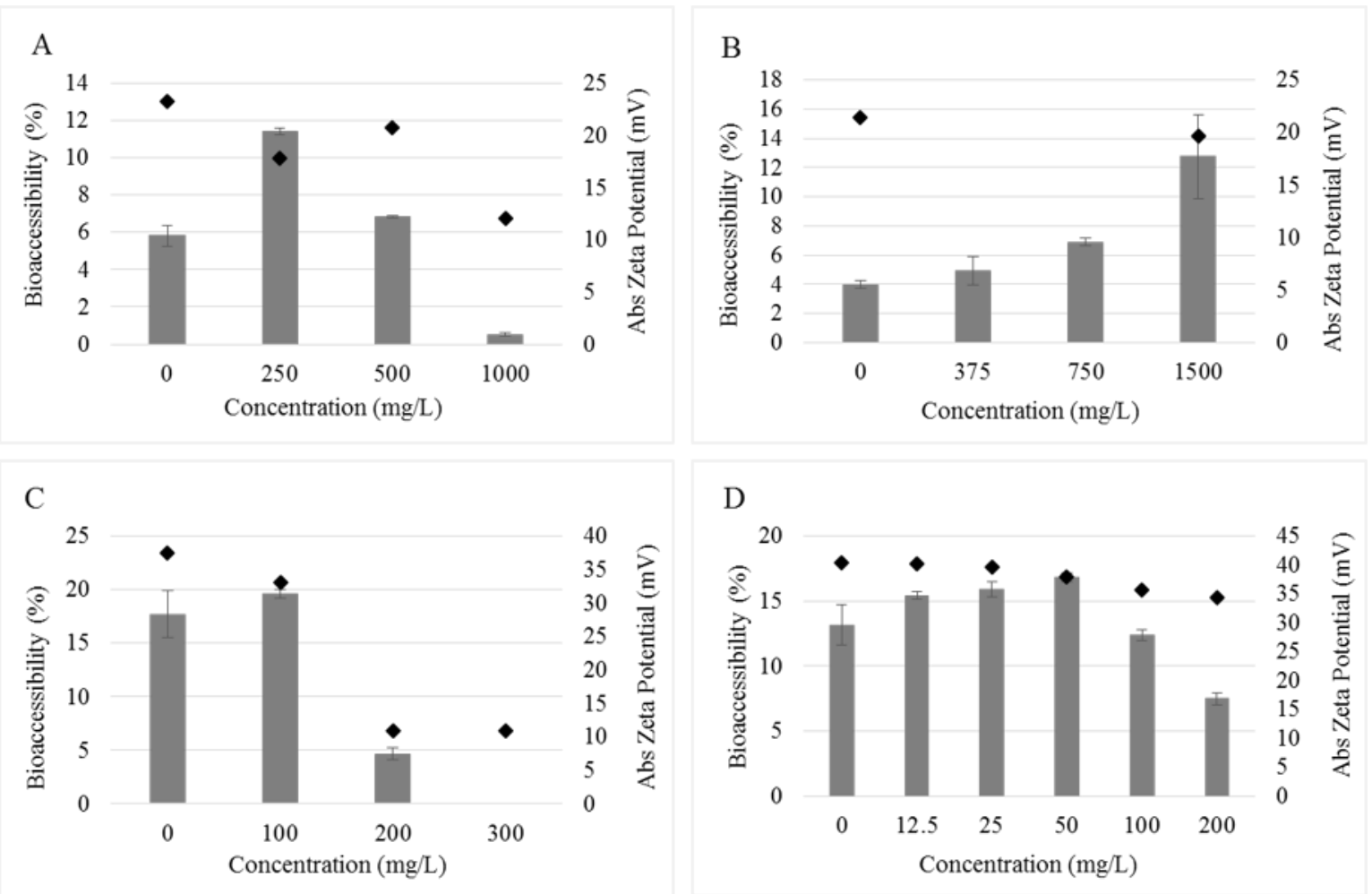

708

709

Figure 6

710 

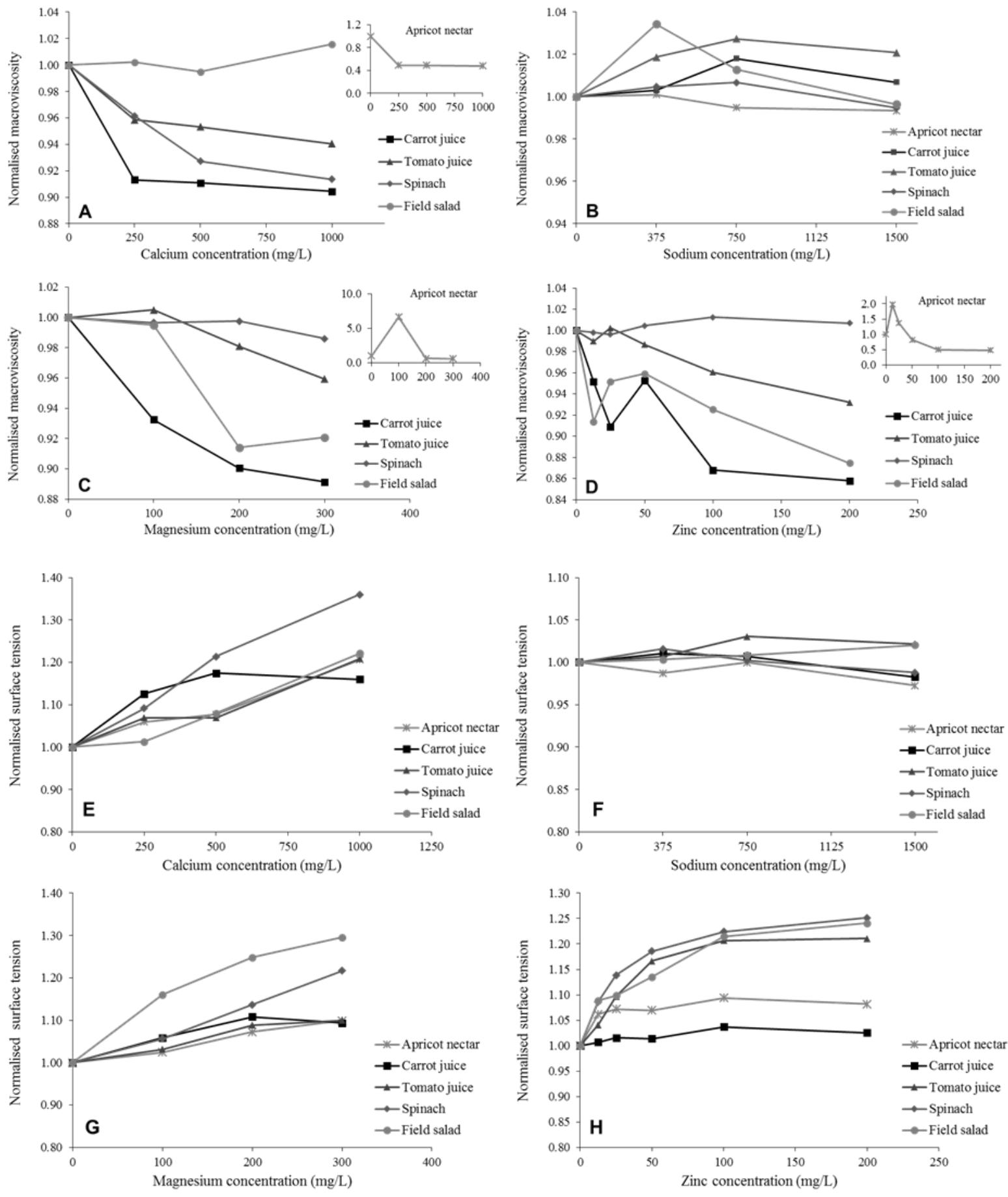

$713 \quad$ Figure 7 